\title{
KOMPOSIT KARET ALAM DAN NANOSILIKA SEKAM PADI TERHADAP SIFAT MEKANIK DAN REOLOGI VULKANISAT KARET
}

\author{
COMPOSITES OF NATURAL RUBBER AND RICE HUSK NANOSILICA ON \\ MECHANICAL AND RHEOLOGY PROPERTIES OF RUBBER VULCANIZATES
}

\author{
Popy Marlina $^{1 *}$ dan Hari Adi Prasetya ${ }^{1}$ \\ ${ }^{1}$ Balai Riset dan Standardisasi Industri Palembang \\ Jalan Perindustrian II, KM.9 No.12, Sukarami, Palembang \\ *main contributor and corresponding author \\ email : popy_marlina@yahoo.co.id
}

Diterima: 07 April 2019; Direvisi : 19 Juli 2019 - 24 Juli 2019; Disetujui: 25 Juli 2019

\begin{abstract}
Abstrak
Nanosilika sekam padi dapat digunakan sebagai bahan pengisi alternatif dalam pembuatan vulkanisat karet. Penelitian ini bertujuan untuk mengetahui pengaruh nanosilika sekam padi terhadap sifat mekanik dan reologi vulkanisat karet dan dibandingkan dengan bahan pengisi carbon black pada pembuatan vulkanisat karet. Pengaruh konsentrasi nanosilika sekam padi (10, 20, 30, 40 dan 50 phr) pada masing- masing konsentrasi terhadap kekerasan, pampatan tetap, modulus $300 \%$, modulus torsi, laju pemasakan optimum, dan waktu scorch. Penelitian eksperimental menggunakan Rancangan Acak Lengkap non Faktorial dan setiap perlakuan diulang sebanyak tiga kali. Hasil pengujian mekanis dan reologi menunjukkan tren dan tidak ada perbedaan nilai yang signifikan antara nanosilika sekam padi dan carbon black yang digunakan sebagai bahan pengisi. Perlakuan terbaik diperoleh pada konsentrasi nanosilika sekam padi $30 \mathrm{phr}$, dan konsentrasi carbon black 40 phr. Vulkanisat karet dengan bahan pengisi carbon black menunjukkan kekerasan, modulus $300 \%$, modulus torsi yang lebih tinggi, namun laju pemasakan optimum, pampatan tetap, dan waktu scorch lebih rendah dari pada nanosilika sekam padi. Nanosilika sekam padi dapat menjadi pengganti carbon black yang baik untuk produk-produk karet dengan biaya dan pampatan tetapnya dipersyaratkan.
\end{abstract}

Kata kunci : nanosilika sekam padi, sifat mekanik, reologi, vulkanisat karet.

\begin{abstract}
The rice husk nanosilika can be used as a filler in the making of rubber vulcanizates. This research aimed to determine the effect of rice husk nanosilika on the mechanical and rheology properties of the rubber vulcanizates compared with carbon black filled rubber vulcanizates. The effect of rice husk nanosilika consentrations (10, 20,30, 40 and 50 phr) on the hardness, compression set, modulus $300 \%$, torque modulus, cure time and scorch time. The experimental research used non Factorial Completely Randomized Design and each treatments was replicated three times. The results of the mechanical and rheology testing presented similar trends and there is no significant difference for both carbon black filled rubber vulcanizates. The best treatment was obtained at the concentration of nanosilica rice husk $30 \mathrm{phr}$, and the concentration of carbon black 40 phr. Rubber vulcanized with carbon black fillers show hardness, 300\% modulus, higher torque modulus, optimum cure, compression sit, and lower scorch time than nanosilica rice husk. Rice husk nanosilica can be a good substitute for carbon black for products where cost and compression set required.
\end{abstract}

Keyword : rice husk nanosilika, mechanical properties, rheologi, rubber vulcanizates.

\section{PENDAHULUAN}

Bahan pengisi merupakan bahan aditif utama dalam pencampuran karet alam. Bahan pengisi yang ditambahkan dalam matriks karet alam dapat meningkatkan sifat seperti kekuatan tarik, modulus, ketahanan sobek, ketahanan kikis, kekakuan dan kemampuan proses dan mengurangi biaya produksi (Gheller et al, 2016; Okieimen and Imanah, 2003).

Salah satu cara untuk mengatasi ketergantungan kebutuhan bahan pengisi penguat untuk pembuatan kompon karet adalah dengan memanfaatkan penganekaragaman sumber daya alam terbarukan yang mempunyai potensi besar, biaya produksi yang murah, ketersediaan yang melimpah dan ramah 
lingkungan. Sekam padi adalah salah satu limbah pertanian dengan potensi besar untuk aplikasi industri. Sekam padi adalah bahan berbasis selulosa yang sangat tersedia dan menunjukkan sifat menarik seperti ketangguhan, tahan terhadap cuaca dan komposisi kimia yang unik. Penelitian ini menggunakan silika dari sekam padi sebagai bahan pengisi vulkanisat karet berupa silika. Silika merupakan bahan pengisi penguat selain carbon black yang dapat digunakan dalam pembuatan vulkanisat karet.

Interaksi bahan pengisi dan karet dijelaskan oleh kesesuaian bahan pengisi dengan karet, atraksi bahan pengisi sendiri dan kemampuan membentuk sebuah jaringan (Haghigat et al., 2007).

Efisiensi penguatan matrik karet dalam proses vulkanisasi tergantung pada ukuran partikel, bentuk partikel, dispersi partikel, luas permukaan, reaktivitas permukaan, struktur pengisi dan kualitas ikatan antara pengisi dan matriks karet (Egwaikhide et al, 2013). Ukuran partikel bahan pengisi, dapat mempengaruhi sifat fisik kompon karet. Semakin kecil ukuran partikel bahan pengisi yang digunakan, maka akan dapat meningkatkan kekerasan, kekuatan tarik, ketahanan kikis dan pampatan tetap. Partikelpartikel yang berukuran kecil memiliki luas permukaan interaksi yang tinggi. Semakin banyak partikel yang berinteraksi, semakin kuat pula material. Hal inilah yang membuat ikatan antar partikel semakin kuat sehingga meningkatkan sifat mekanik material (Hadiyawarman, 2008; Ulfah et al, 2015).

Ada upaya luas di dunia untuk menerapkan nanofiller dalam produksi komposit polimer dengan karakteristik spesifik (Kashani and Samadi, 2015). Penggabungan pengisi nano meningkatkan sifat mekanik, listrik, optik dan lainnya dari komposit polimer tanpa mengorbankan terlalu banyak sifat baik seperti ketangguhan yang diperdagangkan untuk kekakuan seperti yang ditemukan pada serat karbon yang diisi karet.

Penelitian

pengembangan

komposit karet yang diisi partikel nano telah banyak dilakukan melalui penggabungan bahan berskala nano, diantaranya Midhun et al, 2013, menghasilkan sifat mekanik karet kompon yang lebih tinggi dibandingkan silika komersil. Pengaruh pengisi semi nano dari sekam padi terhadap sifat mekanik karet alam terepoksidasi menunjukkan trend dan nilai yang sangat baik dibandingkan dengan menggunakan bahan pengisi carbon black (Ojinmah et al, 2017). Lay et al, 2013, menggunakan bahan pengisi nanosilika pada karet alam komposit, hasil penelitian menunjukkan kekuatan tarik tertinggi dan waktu pemasakan yang paling singkat dibandingkan dengan bahan pengisi lainnya dan kekuatan sobek meningkat dengan meningkatnya konsentrasi nanosilika.

Tujuan penelitian ini mempelajari pengaruh konsentrasi nanosilika sekam padi terhadap sifat mekanik dan reologi vulkanisat karet. Diharapkan dengan pengembangan komposit karet alam dan nanosilika sekam padi dalam pembuatan kompon karet akan dihasilkan barang jadi karet yang elastis dan tahan terhadap gesekan, sehingga pemakaian karet dapat lebih lama.

\section{BAHAN DAN METODA}

\section{Bahan}

Bahan - bahan yang digunakan dalam penelitian ini adalah Nitrille Butadiena Rubber (NBR), SIR 20, sulfur, $\mathrm{ZnO}$, asam stearat, Trimethyl Quinon (TMQ), Tetramethyl Thiuram Disulfide (TMTD), NCyclohexyl-2-benzothiazylsulfenamide

(CBS), Minyak minarek, nanosilika sekam padi (Laboratorium Pusat Penelitian Fisika LIPI)

\footnotetext{
Alat

Peralatan yang digunakan pada penelitian ini adalah timbangan metler p1210 kapasitas $1200 \mathrm{~g}$, timbangan duduk merek Berkel kapasitas $15 \mathrm{~kg}$, open mill L $40 \mathrm{~cm}$ D18 cm kapasitas $1 \mathrm{~kg}$, cutting scraf besar, alat press, cetakan sheet, autoclave, glassware, furnace, ayakan 400 mesh, shaker dan gunting
} 
Metoda Penelitian

Rancangan Percobaan

Penelitian dilakukan dalam skala laboratorium menggunakan metode Rancangan Acak Lengkap (RAL) non faktorial. Perlakuan variasi konsentrasi nanosilika yaitu :10, 20, 30, 40 dan 50 phr, masing-masing perlakuan diulang 3 (tiga) kali.

Tabel 1. Formula kompon karet

\begin{tabular}{lccccc}
\hline \multirow{2}{*}{ Formula } & \multicolumn{5}{c}{ Perlakuan (phr) } \\
\cline { 2 - 6 } & $\mathbf{1}$ & $\mathbf{2}$ & $\mathbf{3}$ & $\mathbf{4}$ & $\mathbf{5}$ \\
\hline SIR 20 & 100 & 100 & 100 & 100 & 100 \\
Nanosilika & 10 & 20 & 30 & 40 & 50 \\
sekam padi & 2 & 2 & 2 & 2 & 2 \\
6PPD & 2 & 1 & 1 & 1 & 1 \\
TMQ & 1 & 5 & 5 & 5 & 5 \\
ZnO & 5 & 2 & 2 & 2 & 2 \\
Asam & 2 & 3 & 3 & 3 & 3 \\
stearat & 3 & 2 & 2 & 2 & 2 \\
CBS & 2 & 1 & 1 & 1 & 1 \\
TMTD & 1 & 1 & 3 & 3 & 3 \\
Sulfur & 3 & 3 &
\end{tabular}

Tahapan Penelitian :

\section{Prosedur Pembuatan Kompon Karet Penimbangan}

Bahan yang diperlukan untuk masing-masing formulasi kompon ditimbang sesuai perlakuan. Jumlah dari setiap bahan di dalam formulasi kompon dinyatakan dalam PHR (berat per seratus karet).

\section{Mixing (pencampuran)}

Proses pencampuran dilakukan dalam gilingan terbuka (open mill), yang telah dibersihkan. Selanjutnya dilakukan proses :

Mastikasi karet alam SIR 1-3 menit, dilanjutkan pencampuran polymer dengan bahan kimia (pembuatan kompon karet/vulkanisasi), meliputi bahan pengisi nanosilika sekam padi setiap sisi dipotong sampai dua atau tiga kali selama 3-8 menit, bahan penggiat/activator, $\mathrm{ZnO}$ dan asam stearat ditambahkan, dipotong setiap sisi satu sampai tiga kali selama 23 menit. Antioksidan, TMQ dan 6PPD ditambahkan, dipotong setiap sisi sampai 3 kali selama 2-3 menit. Pelunak (softener) minarek oil ditambahkan, setiap sisi dipotong sampai dua atau tiga kali selama 3-8 menit. Accelerator TMTD dan CBS ditambahkan, setiap sisi dipotong dua atau tiga kali selama 1-3 menit. Agen Si69 ditambah. Vulkanisator sulfur ditambahkan sampai homogen. Kompon dikeluarkan dari open mill dan ditentukan ukuran ketebalan lembaran kompon dengan menyetel jarak roll pada cetakan sheet, dikeluarkan dan diletakkan diatas plastik transfaran. Kompon di press kemudian vulkanisat yang dihasilkan dipotong disesuaikan dengan barang jadi yang akan dibuat.

\section{Peubah yang diamati}

Peubah yang diamati meliputi sifat mekanik, yaitu kekerasan, pampatan tetap (Suhu $140{ }^{\circ} \mathrm{C}$, selama 24 jam) dan modulus $300 \%$. Sifat rheologi, yaitu modulus torsi, laju pematangan optimum dan waktu scorch.

\section{HASIL DAN PEMBAHASAN}

\section{Sifat Mekanik}

Nilai kekerasan vulkanisat karet semakin besar menunjukkan bahwa vulkanisat karet semakin keras (semakin tidak elastis). Hasil pengujian kekerasan vulkanisat karet terendah diperoleh pada perlakuan vulkanisat karet dengan bahan pengisi nanosilika sekam padi dan vulkanisat karet dengan bahan pengisi carbon black, pada konsentrasi $10 \mathrm{phr}$, yaitu 56 Shore A dan 59 Shore A. Hasil pengujian vulkanisat karet tertinggi diperoleh pada masing-masing perlakuan vulkanisat karet dengan bahan pengisi nanosilika sekam padi $30 \mathrm{phr}$, yaitu 64 Shore A dan vulkanisat karet bahan pengisi carbon black 40 phr, yaitu 67 Shore A. Hasil pengujian kekerasan vulkanisat karet dapat dilihat pada Gambar 1 


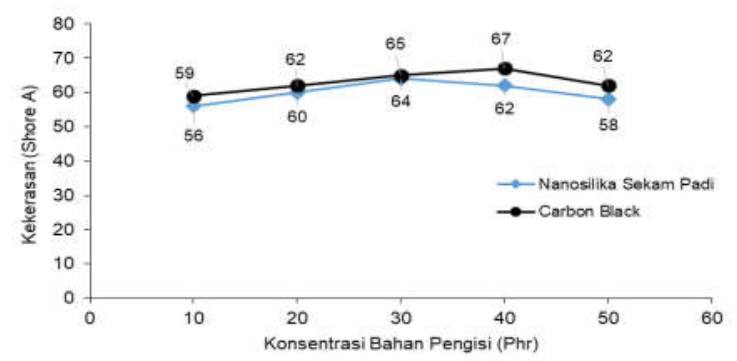

Gambar 1. Kekerasan vulkanisat karet dengan variasi bahan pengisi

Kekerasan vulaknisat karet dengan pengisi nanosilika sekam padi dan vulkanisat pengisi carbon black meningkat dengan meningkatnya konsentrasi bahan pengisi dan mencapai optimum pada konsentrasi nano silika sekam padi $30 \mathrm{phr}$, dan konsentrasi carbon black 40 phr. Semakin banyak partikel bahan pengisi masuk kedalam molekul karet, elastisitas karet akan berkurang, menghasilkan vulkanisat karet yang lebih kaku (Hassan et al 2012; Chuayjuljit et al., 2001; Omofuma et al., 2011). Kekerasan juga dipengaruhi oleh ukuan partikel bahan pengisi. Semakin kecil ukuran partikel, pori-pori silika sekam padi akan semakin besar, maka luas permukaan silika semakin bertambah. Silika sekam padi dalam penelitian ini mempunyai ukuran partikel 0,35 hingga $0,40 \mu \mathrm{m}$, sehingga dengan meningkatnya onsentrasi silika sekam padi, akan mengakibatkan semakin meningkatnya kemampuan berinteraksi dengan molekul karet, sehingga kompon lebih kaku dan keras. Nilai kekerasan vulkanisat karet yang diisi carbon black lebih tinggi dibandingkan dengan vulkanisat karet yang diisi nanosilika sekam padi. Hal ini disebabkan penetrasi carbon black yang lebih baik dalam matriks karet, dibandingkan dengan pengisi nanosilika sekam padi. Kekerasan kompon karet akan meningkat biasanya pada penggabungan bahan pengisi, terutama ketika ukuran partikel bahan pengisi besar. Ukuran partikel carbon black yang lebih besar (400 mesh) dari ukuran partikel silika sekam padi, ketika berinteraksi dengan matrik karet akan menghasilkan kekerasan yang lebih besar. Kekerasan juga merupakan faktor rapat ikatan silang karet, semakin banyak ikatan silang yang terbentuk selama vulkanisasi semakin sulit vulkanisasi akhir terjadi(Ojinmah et al., 2017). Oleh karena itu, pengisi karbon hitam membentuk ikatan silang yang lebih kuat dengan matriks karet dibandingkan pengisi nanosilika sekam padi.

Pampatan tetap untuk memprediksi kinerja vulkanisat karet selama pemakaian. Tingkat kompresi menentukan masa pakai dan penerapan vulkanisat karet untuk barang jadi karet tertentu. Nilai pampatan tetap terendah diperoleh pada konsentrasi tertinggi bahan pengisi (50 phr), yaitu 25,67\% dengan bahan pengisi nanosilika sekam padi dan $21,63 \%$ dengan bahan pengisi carbon black. Hasil pengujian pampatan tetap vulkanisat karet dapat dilihat pada Gambar 2.

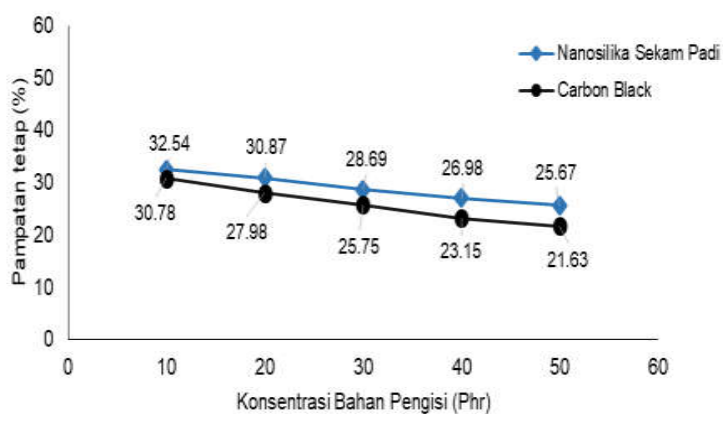

Gambar 2. Pampatan tetap vulkanisat karet dengan variasi bahan pengisi

Hasil pengujian pampatan tetap vulkanisat karet berdasarkan Gambar 2, menunjukkan semakin besar konsentrasi bahan pengisi nanosilika sekam padi dan carbon black yang ditambahkan, nilai pampatan tetap semakin menurun. Nilai pampatan tetap vulkanisat karet yang semakin kecil menunjukkan bahwa vulkanisat karet semakin elastis. Penurunan pampatan tetap karena adanya peningkatan konsentrasi bahan pengisi dalam matriks polimer karet, sehingga ruang kosong dalam matriks berkurang dan akibatnya persentase pampatan tetap menurun. (Amoke et al, 2017), selain itu akan terjadi rapat ikatan 
silang karet yang lebih tinggi karena interaksi bahan pengisi saat vulkanisasi berlangsung, sehingga ruang gerak rantai karet dibatasi dan bisa meregang lebih sedikit ketika vulkanisat diberi beban. Nilai pampatan tetap vulkanisat karet dengan bahan pengisi carbon black lebih rendah daripada vulkanisat dengan bahan pengisi nanosilika sekam padi, hal ini disebabkan ukuran partikel nanosilika sekam padi yang lebih kecil Adanya partikel bahan pengisi yang semakin kecil maka makin luas permukaan, menunjukkan makin banyak gugus fungsional bahan pengisi yang berikatan dengan molekul karet, sehingga interaksi yang terjadi baik secara fisika dan kimia akan semakin baik (Vichitcholchai et al., 2012; Marlina et al, 2014).

Gambar 3 menunjukkan peningkatan nilai modulus vulkanisat karet dengan semakin bertambahnya bahan pengisi dan mencapai optimum pada konsentrasi nanosilika sekam padi $30 \mathrm{phr}$ dan konsentrasi carbon black 40 phr.

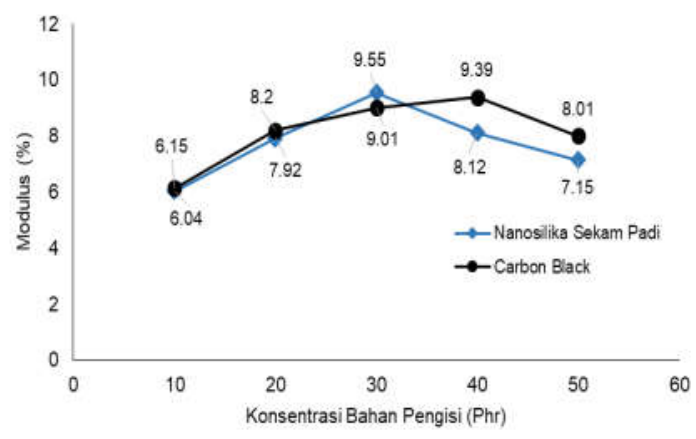

Gambar 3.Modulus vulkanisat karet dengan variasi bahan pengisi

Modulus vulkanisat karet dengan bahan pengisi carbon black lebih tinggi dari vulkanisat dengan pengisi nanosilika sekam padi, hal ini menunjukkan interaksi yang lebih baik antara carbon black dengan matriks karet. Efek penguatan bahan pengisi dipengaruhi oleh faktorfaktor yang meliputi dispersi pengisi, luas permukaan, reaktivitas permukaan, kapasitas ikatan (kualitas), dan ukuran partikel (Razif et al, 2007). Bahan pengisi dengan kandungan karbon lebih tinggi, memberikan penguatan yang lebih besar daripada yang memiliki kandungan karbon lebih rendah karena karbon itu sendiri merupakan pengisi penguat yang sangat baik (Esteves et al, 2009), sehingga vulkanisat karet dengan bahan pengisi carbon black menunjukkan modulus yang lebih tinggi dibandingkan dengan vulkanisat dengan bahan pengisi nanosilika sekam padi. Silika sekam padi sebagai bahan pengisi sangat mudah teraglomerasi, sehingga dapat membuat rongga-rongga kosong yang mengakibatkan ikatan antarmuka yang buruk antara bahan pengisi dan matriks karet.

\section{Sifat Rheologi}

Hasil pengujian karakteristik pematangan kompon karet diperoleh dari kurva Rheometer. Kurva ini memberikan informasi mengenai waktu optimum tejadinya proses vulkanisasi (T90), waktu scorch (Ts2) dan modulus torsi optimum (M90). Besaran-besaran ini diperlukan untuk pembuatan barang jadi karet. Dalam pembuatan barang jadi karet, waktu vulkanisasi yang lambat diperlukan untuk kompon tebal, sedangkan waktu vulkanisasi yang singkat biasanya untuk kompon tipis. Hasil pengujian sifat reologi vulkanisat karet disajikan pada Gambar 4. 


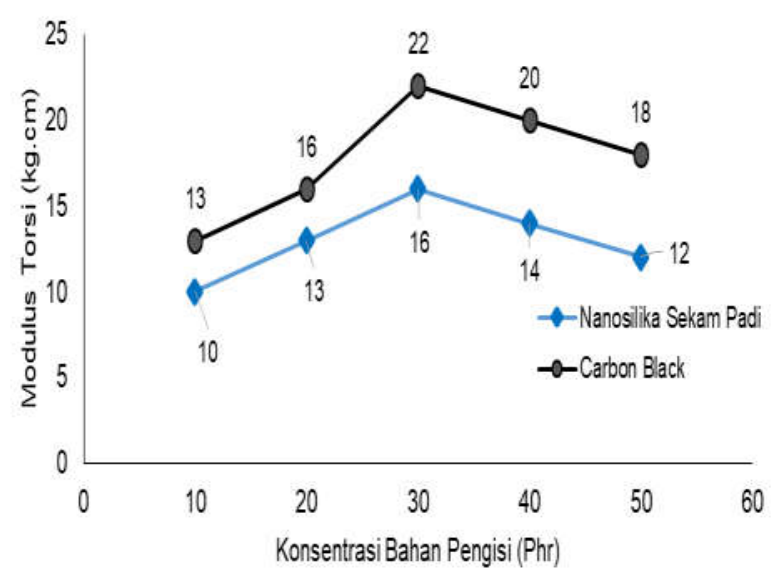

(a)

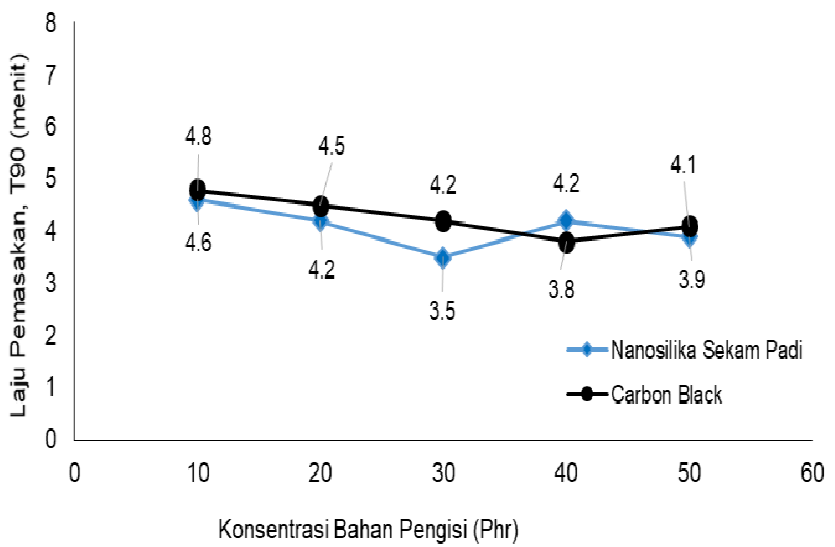

(b)

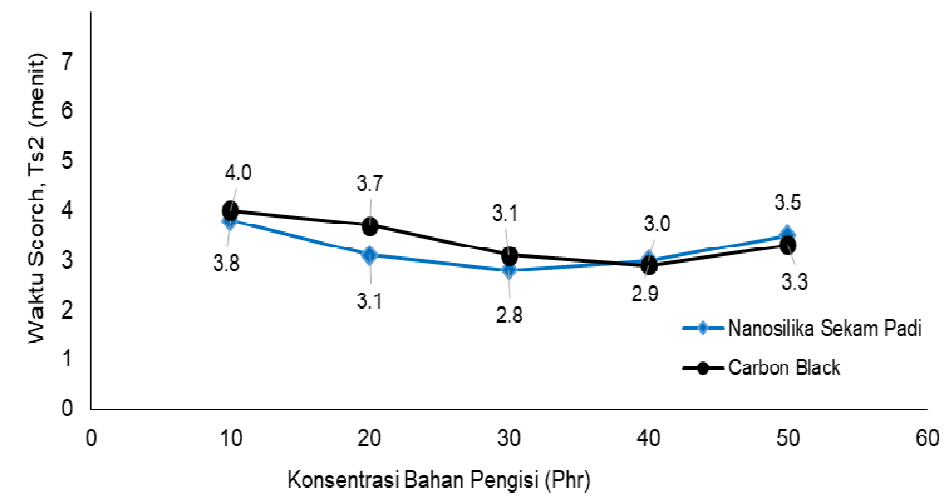

(c)

Gambar 4. Modulus torsi (a), laju pemasakan (b) dan waktu scorch vulkanisat karet (c)

Berdasarkan hasil pengujian reologi kompon karet, pada Gambar 4(a), terdapat kecenderungan modulus torsi kompon karet naik sampai mencapai nilai maksimum dan kemudian turun lagi, dapat dilihat bahwa semakin meningkat konsentrasi bahan pengisi, nilai torsi minimum dan torsi maksimum kompon karet meningkat. Hal ini menunjukkan bahwa penggabungan bahan pengisi ke dalam matriks karet menghasilkan viskositas dan modulus yang lebih tinggi pada komposit karet. Bahan pengisi carbon black memiliki pengaruh lebih besar pada peningkatan modulus torsi kompon karet dibanding nanosilika sekam padi. Modulus torsi tergantung pada rapat ikatan silang dan keterikatan rantai. Ikatan antar atom $\mathrm{C}$ pada molekul karet berinteraksi dengan rantai $\mathrm{C}$ carbon black, sehingga terbentuk banyak ikatan silang baru. Besarnya nilai modulus torsi dapat digunakan sebagai indikator banyaknya ikatan silang yang terbentuk sebagai hasil vulkanisasi (Ahmed et al., 2012).

Gambar 4(b), semakin tinggi konsentrasi bahan pengisi, laju pemasakan akan menurun dan mencapai optimum pada konsentrasi perlakuan konsentrasi nanosilika sekam padi 30 phr, dengan nilai sebesar 3,5 menit dan perlakuan konsentrasi carbon black $50 \mathrm{phr}$, yaitu 4.1 menit. Hal ini disebabkan semakin 
Popy Marlina Hari Adi Prasetya

Komposit Karet Alam dan Nanosilika Sekam Padi terhadap Sifat Mekanik dan Reologi Vulkanisat Karet

banyak bahan pengisi yang ditambahkan ke senyawa karet, bagian karet menjadi kurang dan waktu untuk membentuk ikatan silang juga menurun. Laju pemasakan kompon karet lebih tinggi dengan bahan pengisi carbon black, dibandingkan dengan bahan pengisi nanosilika sekam padi. Hal ini terkait dengan ukuran partikel carbon black yang lebih besar dan area permukaan yang menghambat pembentukan lebih banyak ikatan silang sulfur selama vulkanisasi (Salim et al, 2013). Konsentrasi bahan pengisi meningkat, maka waktu untuk penggabungan juga lebih lama. Akibatnya, terjadi pengurangan waktu hangus $\left(\mathrm{ts}_{2}\right)$ dan waktu pemasakan $\left(\mathrm{t}_{90}\right)$ karena ikatan silang yang terbentuk belum sempurna (Daud et al., 2017). Waktu vulkanisasi yang lebih cepat ini sangat diperlukan untuk proses produksi yang banyak (massal) kaitannya dengan efisiensi waktu dan penggunaan energi.

Berdasarkan Gambar 4(c), semakin tinggi konsentrasi bahan pengisi, semakin menurun waktu scorch kompon karet dan mencapai optimum pada perlakuan konsentrasi nanosilika sekam padi $30 \mathrm{phr}$, yaitu 2,8 menit dan perlakuan konsentrasi carbon black 40 phr, yaitu 2,9 menit. Waktu scorch terendah diperoleh pada perlakuan kompon karet dengan nanosilika sekam padi. Untuk memperoleh penguatan yang optimum maka partikel bahan pengisi tersebut harus tersebar secara merata dalam komponen karet. Semakin kecil ukuran partikel bahan pengisi maka pada penambahan dengan jumlah berat yang sama, akan meningkatkan sifat fisik dan mekanik kompon karet (Ngamsurata et al., 2011). Waktu scorch juga merupakan pengukuran vulkanisasi dini pada matriks karet dan merupakan indikator keselamatan olah (scorch safety).

\section{KESIMPULAN}

Penggunaan bahan pengisi nanosilika sekam padi berpengaruh terhadap sifat mekanik dan reologi vulkanisat karet, meliputi kekerasan, pempatan tetap, modulus torsi, laju pemasakan (T90) dan waktu scorch (ts2).
Perlakuan terbaik diperoleh pada konsentrasi nanosilika sekam padi $30 \mathrm{phr}$, dan konsentrasi carbon black $40 \mathrm{phr}$. Vulkanisat karet dengan bahan pengisi carbon black menunjukkan kekerasan, modulus $300 \%$, modulus torsi yang lebih tinggi, namun laju pemasakan optimum, pampatan tetap, dan waktu scorch lebih rendah dari pada nanosilika sekam padi. Vulkanisat karet dengan bahan pengisi nanosilika sekam padi dapat digunakan untuk pembuatan produk karet yang memerlukan tekanan lebih rendah tetapi pampatan tetap lebih tinggi, kuat tekan, dan perpanjangan putus. Bahan pengisi nanosilika sekam padi dapat berfungsi sebagai bahan pengisi yang lebih baik sebagai pengganti carbon black.

\section{UCAPAN TERIMA KASIH}

Penulis mengucapkan terima kasih kepada Bapak Bambang Sugiyono, Ibu Mimi Kurnia Yusya dan Bapak Agus Sukarta (Laboratorium Fisika BATAN) yang telah membantu kegiatan penelitian.

\section{DAFTAR PUSTAKA}

Ahmed, K., Sirajuddin, S.N., Raza, N.Z., dan Shirin, K. (2012). Cure Characteristics, Mechanical and Swelling Properties of Marble Sludge Filled EPDM Modified Chloroprene Rubber Blends. Advances in Materials Physics and Chemistry. 2 : 90-97.

Amoke, A, Ogbobe. O, Tenebe, G.O, Ichetaonye, S.I and Ayo, M.D. (2017). AmokePhysico-Mechanical Properties and Water Absorption Behavior of Natural Rubber Vulcanizates Filled With Sawdust. 8(1) :108-114.

Chuayjuljit, S, Eiumnoh, S, and Potiyaraj, P. 2001. Using silica from rice husk as a reinforcing filler in natural rubber. J. Sci. Chula University, 26(2) : 127-138.

Daud, S., Ismail, H., dan Bakar, A.A. (2016). The Effect of 3aminopropyltrimethyoxysilane (AMEO) as a Coupling Agent on Curing and Mechanical Properties of Natural 
Rubber/Palm Kernel Shell Powder Composites. Procedia Chemistry. 19 : $327-334$.

Egwaikhide, A. P, Okieimen, F. E and Lawal. U. (2013). Rheological and mechanical properties of natural rubber compounds filled with carbonized palm kernel husk and carbon black (N330). Science Journal of Chemistry. 1(5): 50-55.

Esteves, S, Vargas, S, Castano, V.M and Rodriguez, R. (2009). Silica NanoParticles Produced by Worms Through Biodigestion Process of Rice Husk, Journal of Non-crystalline solids. 335 (14), 844-850.

Gheller. J.O, Manoela, V.E and Oliviera, V. (2016). Polymer-filler interactions in a tire compound reinforced with silica. Journal of Elastomer \& Plastics. 48(3) : 217-226.

Hadiyawarman, 2008. Fabrikasi material nanokomposit superkuat, ringan dan transparan menggunakan metode simple mixing. Jurnal Nanosains \& Nanoteknologi 1 (1) : 48-54.

Haghighat, M.A, Khorasani, S.NM, dan Zadhoush. 2007. Filler-rubber interactions in a cellulose-filled styrene butadiene rubber composites. J. Appl. Polym. Sci., 10:748 - 754.

Hassan, EJ Ogherevwet and V Aigbodion. (2012). Potential of Maize Stalk Ash as Reinforcements for Polyester Composites. Journal of Minerals and Materials Characterization and Engineering. 11 (4) : 543 - 557.

Kashani, M.R and Samadi. (2015). Physicalmechanical properties of carbon black nanoclay composites of butyl rubber as curing bladder compounds. Plastics, Rubber and Composites 0 (0) : 1-6.

Lay, M. (2013). Effect of Nanosilica Fillers on the Cure Characteristics and Mechanical Properties of Natural Rubber Composites. Advanced Materials Research. 626 : 818-822.

Marlina. P, Pratama. F, Hamzah. B dan Pambayun R. (2014). Pengaruh Suhu dan Lama Penyimpanan terhadap Karakteristik Kompon Karet dengan
Bahan Pengisi Arang Aktif Tempurung Kelapa dan Nano Silika Sekam Padi. Jurnal Dinamika Penelitian Industri. 25 (1) : 41-49.

Midhun Dominic C.D, Sabura Begum, Rani Joseph, Daisy Joseph, Prabith Kumar and Ayswarya E.P. (2013). Synthesis, Characterization and Appilcation of Rice Husk Nanosilica in Natural Rubber. International Journal of Science, Environment and Technology. 2 (5) : 19.

Ngamsurata, S., Boonkerda, K., Leelaadisorna, U., dan Potiyaraja, P. (2011). Curing Characteristics of Natural Rubber Filled with Gypsum. Energy Procedia. 9 : 452 - 458.

Okieimen, F.E and J.E. Imanah (2003); The characterization of agricultural waste products as fillers in NR formulation Nig. J. Polym Sci and Tech. Vol. 3 No 1 210-21.

Ojinmah, N, Uchechukwu, T.O, Ezeh, V.O and Ogbobe, O. (2017). Studies on the Effect of Rice Husk Semi-Nano Filler on the Mechanical Properties of Epoxidized Natural Rubber Composite. European Journal of Advances in Engineering and Technology. 4 (3): 164-171.

Omofuma, F.E, Adeniye, S.A, and Adeleke, $A E$. 2011. The effect of particle sizes on the performance of filler: A Case study of rice husk and wood flour. World Appl. Sci. J., 14(9) : 1347-1352.

Razif, N, Said, S and Ismail, M. (2007). Properties of Rice Husk Powder/Natural Rubber Composite. Journal of Solid State Science and Technology. 15(2) : 83-91.

Ulfah, I.M, Fidyaningsih, R, Rahayu, S, Saputra, D.A, Winarto, D.A and Wisojodharmo L.A. (2015). Influence of carbon black and silica filler on the rheologival and mechanical properties of natural rubber compound. Procedia Chemistry. 16(2015) ; 258-264.

Vichitcholchai N., Na-ronang N., Noisuwan W and Arayapranee W. (2012). Using Rice Husk Ash as Filler in Rubber Industry. Rubber Thai Journal. $1: 48-55$. 